\title{
Schnelle Prüfung von Reibwerten an Schrauben
}

Die beim Anziehen von Schrauben erzielte Vorspannkraft hängt nicht nur vom aufgebrachten Drehmoment ab, sondern auch vom Reibungskoeffizienten $\mu$. Dieser kann selbst bei "gleichen" oder gleich aussehenden Schrauben sehr unterschiedlich ausfallen: Es braucht nur eine andere Beschichtung vorzuliegen, ein neues Schmiermittel eingesetzt worden zu sein - oder es gibt Abweichungen bei den Maßen oder ganz allgemein bei der Oberflächenbeschaffenheit.

"Alle diese Faktoren beeinflussen die Zuverlässigkeit einer Schraubverbindung in erheblichem Maße", teilt Atlas Copco Tools in Essen mit. Ein zu niedriger Reibwert bewirke, dass die Vorspannkraft höher sei als

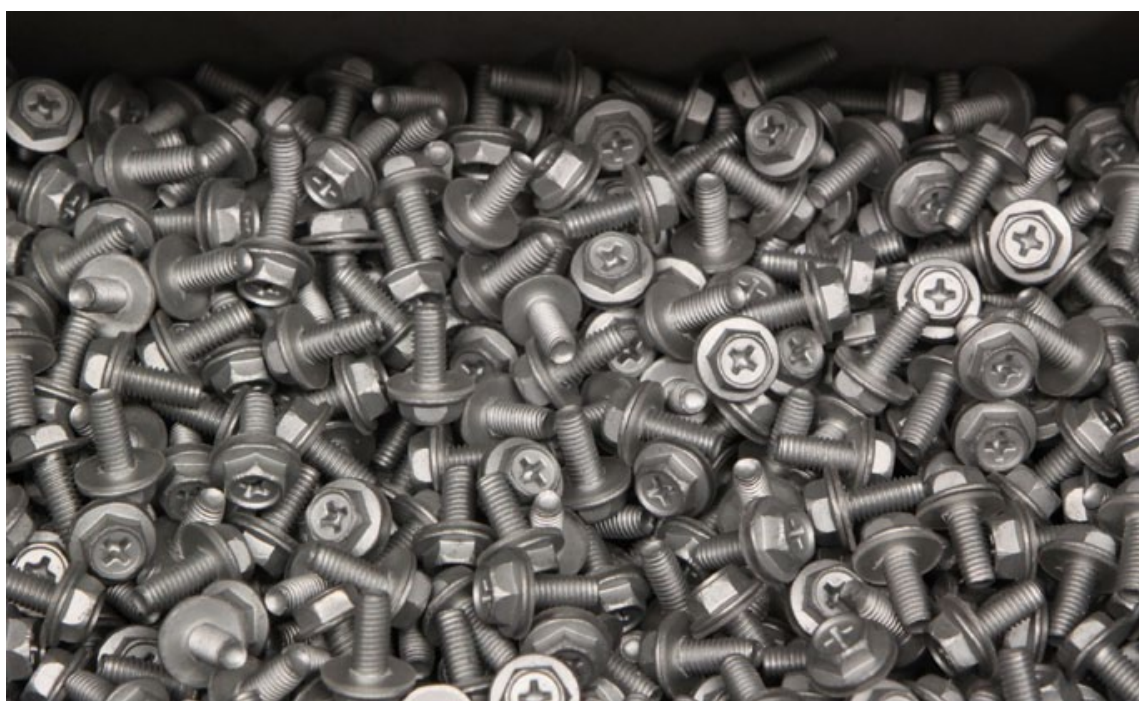
angenommen, was zu einem Schraubenbruch führen könne. Ferner könne ein zu hoher Reibwert eine niedrige Vorspannung bewirken, wodurch sich die Schraube lockern und lösen kann. Daher sei es notwendig, den Reibungskoeffizient auf schnellem und einfachem Wege prüfen zu können. Die Serviceabteilung von Atlas Copco Tools biete diese Analysen allen Kunden direkt vor Ort oder in den eigenen Laboren an. Mit dem BLM- $\mu$-Tester könnten Qualitätssicherer diese Prüfung aber auch selbst direkt an der Fertigungslinie vornehmen. Das Ergebnis stehe dann in beiden Fällen unmittelbar zur Verfügung.

Mit dem mobilen Messwagen können laut Atlas Copco Tools Schraubfallcharakteristiken auch im Labor exakt reproduziert werden. Die benutzerfreundliche Software führe den Anwender schnell zur richtigen Schraube und zur intuitiven Analyse. In nur wenigen Sekunden könne der Bediener entscheiden, ob ein Schraubenlos für die jeweilige Anwendung geeignet ist oder den Vorgaben nicht entspricht.

„Der BLM- $\mu$-Tester ist eine komplette Messeinrichtung mit PC und Touchscreen sowie eingebautem Messwertgeber", heißt es. Es könnten Schrauben mit unterschiedlichen Durchmessern, Längen und Gewinden getestet werden. Der Prüfaufbau sei einfach und schnell zugleich. Es stünden drei Messwertaufnehmer zur Verfügung (TPT 25, TPT 200 und TPT 2000), mit denen Anwender Schrauben der Größen M3 bis M24 prüfen können.

www.innomateria.de

\section{Innovative Werkstoffe von heute für die Produkte von morgen}

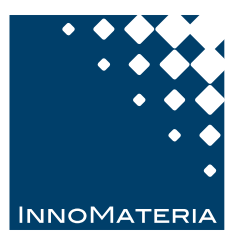

Interdisziplinäre Kongressmesse für innovative Werkstoffe

Köln, 14.-15. Mai 2013

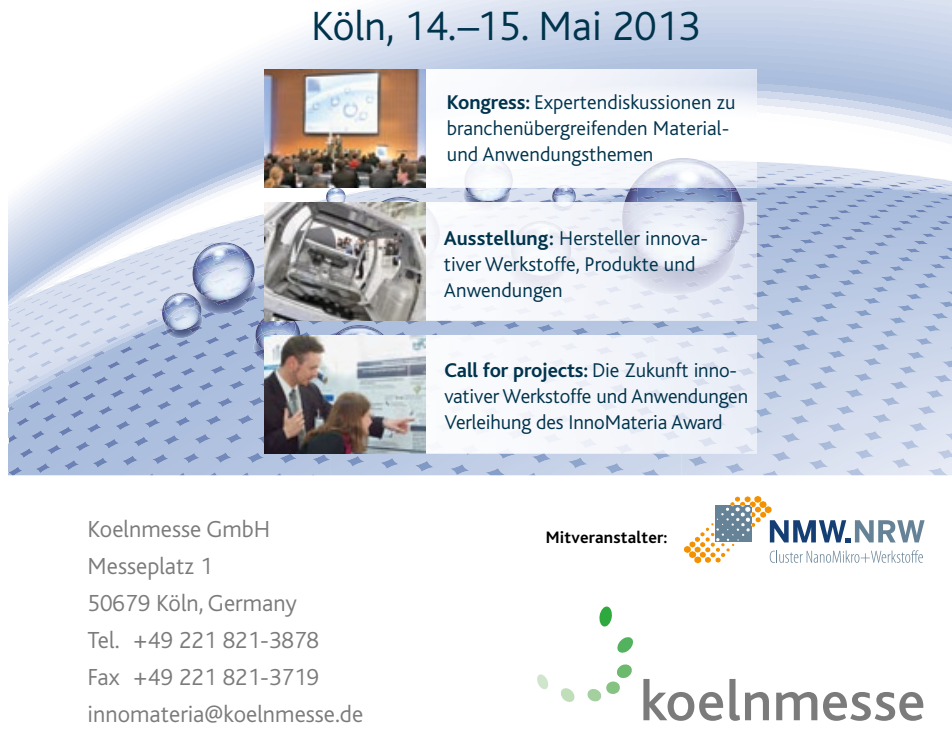

